Article

\title{
Serum Zinc Concentration and Sarcopenia: A Close Linkage in Chronic Liver Diseases
}

\author{
Hiroki Nishikawa *, Hirayuki Enomoto, Kazunori Yoh, Yoshinori Iwata, Yoshiyuki Sakai, \\ Kyohei Kishino, Naoto Ikeda, Tomoyuki Takashima, Nobuhiro Aizawa, Ryo Takata, \\ Kunihiro Hasegawa, Noriko Ishii, Yukihisa Yuri, Takashi Nishimura, Hiroko Iijima and \\ Shuhei Nishiguchi
}

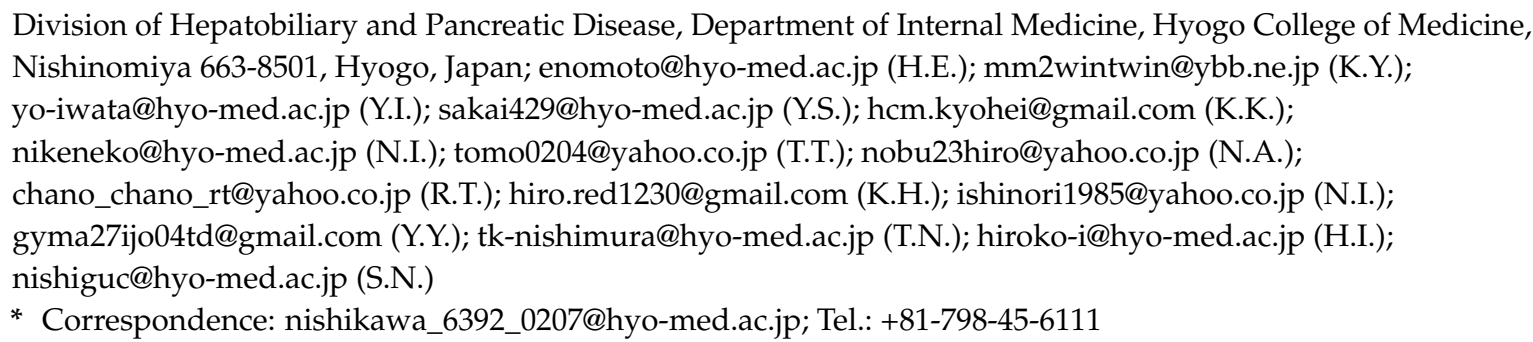

Received: 28 January 2019; Accepted: 7 March 2019; Published: 11 March 2019

\begin{abstract}
We sought to investigate the influence of serum zinc (Zn) concentration on sarcopenia in chronic liver diseases (CLDs, $n=372$, median age $=65$ years, 147 liver cirrhosis (LC) cases (39.5\%)). Sarcopenia was defined by low grip strength and low skeletal muscle mass. Study subjects were divided into the following three groups (High-, Intermediate-, and Low-Zn groups) based on the baseline serum $\mathrm{Zn}$ level. The impacts of serum $\mathrm{Zn}$ concentration on sarcopenia were examined. The median (interquartile range) serum Zn concentration for all cases was $72.85(63.7,81.45) \mu \mathrm{g} / \mathrm{dL}$. The proportions of sarcopenia in the High-Zn, Intermediate-Zn, and Low-Zn groups were $10.75 \%$ (10/93), $11.23 \%(21 / 187)$, and 27.17\% (25/92), respectively $(P=0.9046$ (High vs. Intermediate), $P=0.0007$ (Intermediate vs. Low), $P=0.0044$ (High vs. Low), overall $P$ value $=0.0009$ ). The median serum $\mathrm{Zn}$ concentrations in patients with sarcopenia, pre-sarcopenia, and control were 66.35, 73.1 and $73.8 \mu \mathrm{g} / \mathrm{dL}$, respectively ( $P=0.0234$ (sarcopenia vs. pre-sarcopenia), $P=0.2116$ (pre-sarcopenia vs. control), $P=0.0002$ (sarcopenia vs. control), overall $P$ value $=0.0016$ ). In the multivariate analyses of factors linked to the presence of sarcopenia, Low- $\mathrm{Zn}$ was an independent predictor for all cases $(P=0.0236)$ and LC cases $(P=0.0082)$. In conclusion, $Z n$ deficiency can be an independent predictor for sarcopenia in patients with CLDs.
\end{abstract}

Keywords: chronic liver disease; zinc; sarcopenia; pre-sarcopenia; liver cirrhosis

\section{Introduction}

Zinc $(\mathrm{Zn})$ is an important trace element that is needed for normal cell development, proliferation, and differentiation, and it is also known to be crucial to ensure an appropriate immunological reaction, such as anti-inflammatory effects, anti-oxidant effects, or autophagy [1-4]. Zn deficiency can cause a wide spectrum of clinical presentations, including appetite loss, body hair loss, impaired taste and smell, atrophy of testis, cerebral and immune dysfunction, and impairment of drug excretion ability, and they are frequently observed in chronic liver diseases (CLDs) as Zn homeostasis is primarily regulated in the liver [3,5-9]. Albumin synthesis disability can cause Zn deficiency in patients with liver cirrhosis (LC) $[3,10,11]$. Serum Zn concentrations had the inverse correlation with serum ammonia levels in LC patients [12-14]. The degree of Zn deficiency is reported to correlate well with the severity 
of liver diseases [15]. On the other hand, Zn deficiency-related abnormalities may be covered by $\mathrm{Zn}$ supplementation $[3,5-7,13]$. Katayama et al. reported in their randomized controlled trial that $\mathrm{Zn}$ supplementation therapy can be safe and effective for treating hyperammonemia in LC patients [13]. However, numerous clinical aspects of Zn deficiency have not yet been elucidated in CLD patients.

Skeletal muscle mass (SkMM) decreases by approximately $1 \%$ after the age of 50 years due to the qualitative and quantitative changes in muscle fibers [16]. Sarcopenia is a common syndrome mainly observed in older population and characterized by progressive decline of muscle mass and muscle function resulting in an increased risk of physical disability, decreased quality of life (QOL), and mortality [17-23]. In CLD patients, sarcopenia can also be observed irrespective of age due to protein-energy malnutrition or other metabolic or hormonal disorders specific to CLDs [18,19,21,23-28]. Sarcopenia in CLDs is therefore a serious health problem. Based on these backgrounds, the Japanese Society of Hepatology (JSH) proposed its own criteria for liver disease-related sarcopenia in 2016 [18]. Notably, there is no age restriction for the evaluation of sarcopenia in the JSH guidelines [18]. Numerous evidences for liver disease-related sarcopenia have been accumulated [28-31].

However, as far as we are aware, the association between serum $\mathrm{Zn}$ concentration and sarcopenia in CLD patients is largely unknown. There seems therefore to be a pressing need for clarifying these issues. In this study, we sought to investigate the influence of serum Zn concentration on sarcopenia in patients with CLDs.

\section{Patients and methods}

\subsection{Patients}

A total of 378 CLD patients with data for grip strength (GpS), SkMM using bioimpedance analysis (BIA), and serum Zn concentration were admitted to our institution between November 2013 and August 2018. Because overestimates could occur for the calculation of skeletal muscle mass index (SMI) using BIA in patients with massive ascites, 6 subjects with massive ascites were excluded from the study [19]. Three-hundred and seventy-two patients were consequently included in the current analysis. CLD was determined according to patient medical record, laboratory data, histological findings, and imaging findings. LC diagnosis was also based on histological findings (F4) or imaging findings (presence of varices, deformity of the liver, splenomegaly, etc.).

\subsection{Our Classification Based on the Serum Zn Concentration}

As described later, the median (interquartile range (IQR)) serum $\mathrm{Zn}$ concentration for all cases in the current analysis was $72.85(63.7,81.45) \mu \mathrm{g} / \mathrm{dL}$. Thus, our study subjects were divided into the following three groups based on the baseline serum $\mathrm{Zn}$ level: (A) Low-Zn (L-Zn) group; patients with serum $\mathrm{Zn}$ concentration $<63.7 \mu \mathrm{g} / \mathrm{dL}$ (first quartile). (B) Intermediate-Zn (I-Zn) group; patients with $63.7 \mu \mathrm{g} / \mathrm{dL} \leq$ serum $\mathrm{Zn}$ concentration $\leq 81.45 \mu \mathrm{g} / \mathrm{dL}$ (second or third quartile). (C) High-Zn (H-Zn) group; patients with serum Zn concentration $>81.45 \mu \mathrm{g} / \mathrm{dL}$ (fourth quartile). (Figure 1) The normal range of serum $\mathrm{Zn}$ concentration in our institution is from $80 \mu \mathrm{g} / \mathrm{dL}$ to $130 \mu \mathrm{g} / \mathrm{dL}$. Hypozincemia was thus defined as serum $\mathrm{Zn}$ concentration $<80 \mu \mathrm{g} / \mathrm{dL}$. 


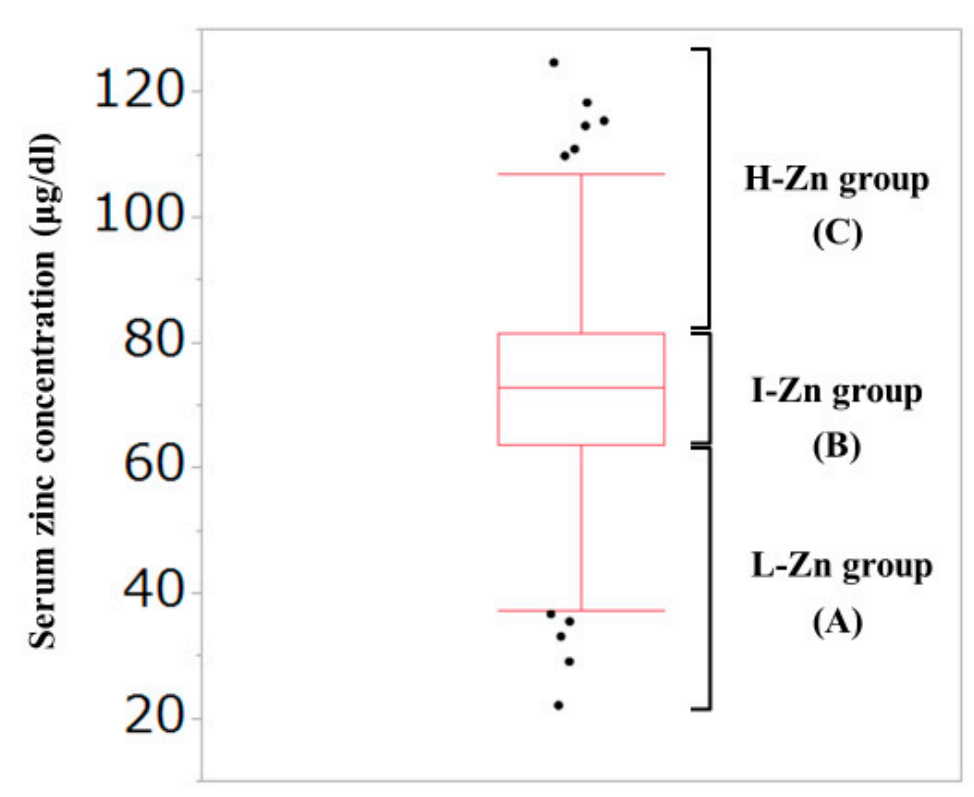

Figure 1. Our classification based on the serum $\mathrm{Zn}$ concentration. The median (interquartile range) serum $\mathrm{Zn}$ concentration for all cases in the current analysis was $72.85(63.7,81.45) \mu \mathrm{g} / \mathrm{dL}$. (A) Low-Zn group; patients with serum $\mathrm{Zn}$ concentration $<63.7 \mu \mathrm{g} / \mathrm{dL}$ (first quartile). (B) Intermediate-Zn group; patients with $63.7 \mu \mathrm{g} / \mathrm{dL}<$ serum $\mathrm{Zn}$ concentration $<81.45 \mu \mathrm{g} / \mathrm{dL}$ (second or third quartile). (C) High-Zn group; patients with serum Zn concentration $>81.45 \mu \mathrm{g} / \mathrm{dL}$ (fourth quartile).

\subsection{Measurement of GpS and SMI for Evaluating Sarcopenia}

GpS was measured according to the current Japanese guidelines [18]. SMI was defined as "appendicular SkMM/(height (m) 2)" using BIA. According to the current Japanese guidelines, patients with decreased $\mathrm{GpS}$ were defined as those with $\mathrm{GpS}<26 \mathrm{~kg}$ for male and $<18 \mathrm{~kg}$ for female. Similarly, patients with decreased SkMM were defined as those with SMI $<7.0 \mathrm{~kg} / \mathrm{m}^{2}$ for male and $<5.7 \mathrm{~kg} / \mathrm{m}^{2}$ for female [18]. In males, patients with GpS $<26 \mathrm{~kg}$ and SMI $<7.0 \mathrm{~kg} / \mathrm{m}^{2}$ were classified as having sarcopenia, those with GS $<26 \mathrm{~kg}$ and SMI $\leq 7.0 \mathrm{~kg} / \mathrm{m}^{2}$ as pre-sarcopenia, those with GS $\leq 26 \mathrm{~kg}$ and SMI $<7.0 \mathrm{~kg} / \mathrm{m}^{2}$ as pre-sarcopenia, and those with GS $\leq 26 \mathrm{~kg}$ and SMI $\leq 7.0 \mathrm{~kg} / \mathrm{m}^{2}$ as control. In female, patients with GS $<18 \mathrm{~kg}$ and SMI $<5.7 \mathrm{~kg} / \mathrm{m}^{2}$ were classified as sarcopenia, those with GS $<18 \mathrm{~kg}$ and SMI $\leq 5.7 \mathrm{~kg} / \mathrm{m}^{2}$ as pre-sarcopenia, those with GS $\leq 18 \mathrm{~kg}$ and $\mathrm{SMI}<5.7 \mathrm{~kg} / \mathrm{m}^{2}$ as pre-sarcopenia, and those with GS $\leq 18 \mathrm{~kg}$ and $\mathrm{SMI} \leq 5.7 \mathrm{~kg} / \mathrm{m}^{2}$ as control.

Firstly, the impacts of serum $\mathrm{Zn}$ concentration on sarcopenia were examined for all cases and several subgroups according to the LC status. Secondly, factors associated with the presence of sarcopenia were studied using univariate and multivariate analyses. Correlation between serum $\mathrm{Zn}$ concentration and baseline characteristics was also examined. The ethics committee of our hospital acknowledged this study (number: 2296). The protocol in the study strictly observed all regulations of the Declaration of Helsinki.

\subsection{Statistical Considerations}

As for continuous parameters, Student's $t$ test, Mann-Whitney U test, Pearson's correlation coefficient $r$, analysis of variance, or Kruskal-Wallis test were employed to assess group difference, as applicable. In categorical parameters, Pearson $\chi^{2}$ test was employed to assess group difference, as applicable. Factors with $P<0.05$ linked to the presence of sarcopenia in the univariate analysis were subjected to the multivariate logistic regression analysis to identify candidate parameters. Baseline factors significantly correlated with serum $\mathrm{Zn}$ concentration in the univariate analysis were also subjected to the multivariate logistic regression analysis to identify candidate parameters. Unless otherwise mentioned, data were indicated as median values (IQR). The threshold for statistical 
significance was set at $P<0.05$. The JMP 13.2 (SAS Institute Inc., Cary, NC, USA) was employed to carry out statistical analysis.

\section{Results}

\subsection{Patient Baseline Characteristics}

Baseline characteristics in our study $(n=372,171$ males and 201 females, median age (IQR) $=65$ $(54,71.75)$ years) were shown in Table 1 . In terms of liver disease etiology, hepatitis $C$ virus was in the majority $(60.2 \%, 224 / 372)$. The median (IQR) serum $\mathrm{Zn}$ concentration for all cases was 72.85 $(63.7,81.45) \mu \mathrm{g} / \mathrm{dL}$. Hypozincemia $(<80.0 \mu \mathrm{g} / \mathrm{dL})$ was identified in 261 patients $(70.2 \%)$. Sarcopenia was observed in 56 patients (15.1\%), while pre-sarcopenia (patients with decreased GpS alone or decreased SkMM alone) was observed in 131 patients (35.2\%). There were 93, 187, and 92 patients in the H-Zn, I-Zn, and L-Zn groups, respectively. The proportions of sarcopenia in the H-Zn, I-Zn, and L-Zn groups were $10.75 \%(10 / 93), 11.23 \%(21 / 187)$, and $27.17 \%(25 / 92)$, respectively $(P$ values: $P=0.9046$ (H-Zn group vs. I-Zn group), $P=0.0007$ (I-Zn group vs. $\mathrm{L}-\mathrm{Zn}$ group), $P=0.0044$ (H-Zn group vs. $\mathrm{L}-\mathrm{Zn}$ group$)$, overall $P$ value $=0.0009)($ Figure $2 \mathrm{~A})$. The median $(\mathrm{IQR})$ serum $\mathrm{Zn}$ concentrations in patients with sarcopenia, pre-sarcopenia, and control were $66.35(54.05,77.425) \mu \mathrm{g} / \mathrm{dL}, 73.1(60.4,82.1)$ $\mu \mathrm{g} / \mathrm{dL}$, and $73.8(67.2,81.85) \mu \mathrm{g} / \mathrm{dL}$, respectively ( $P$ values: $P=0.0234$ (sarcopenia vs. pre-sarcopenia), $P=0.2116$ (pre-sarcopenia vs. control), $P=0.0002$ (sarcopenia vs. control), overall $P$ value $=0.0016$ ) (Figure 2B).

Table 1. Baseline characteristics.

\begin{tabular}{cc}
\hline Variables & All Cases $(\boldsymbol{n}=372)$ \\
\hline Age (years) & $65(54,71.75)$ \\
Gender, male/female & $171 / 201$ \\
$\mathrm{HBV} / \mathrm{HCV} / \mathrm{HBV}$ and $\mathrm{HCV} / \mathrm{NBNC}$ & $53 / 224 / 8 / 87$ \\
Presence of LC, yes/no & $147 / 225$ \\
Body mass index $\left(\mathrm{kg} / \mathrm{m}^{2}\right)$ & $22.6(20.4,25.3)$ \\
Total bilirubin $(\mathrm{mg} / \mathrm{dL})$ & $0.8(0.6,1.1)$ \\
Serum albumin $(\mathrm{g} / \mathrm{dL})$ & $4.1(3.8,4.5)$ \\
Prothrombin time $(\%)$ & $88.5(78.3,96.5)$ \\
Platelet count $\left(\times 10^{4} / \mathrm{mm}^{3}\right)$ & $16.5(11.35,20.7)$ \\
Total cholesterol $(\mathrm{mg} / \mathrm{dL})$ & $179(151,206)$ \\
AST $(\mathrm{IU} / \mathrm{L})$ & $28(21,42)$ \\
ALT $(\mathrm{IU} / \mathrm{L})$ & $23(15,40)$ \\
ALP $(\mathrm{IU} / \mathrm{L})$ & $243(193,318.25)$ \\
GGT $(\mathrm{IU} / \mathrm{L})$ & $28(17,50)$ \\
eGFR $\left(\mathrm{mL} / \mathrm{min} / 1.73 \mathrm{~m}{ }^{2}\right)$ & $83(70,96)$ \\
HbA1c $(\mathrm{NGSP})$ & $5.6(5.4,6.0)$ \\
Serum sodium $(\mathrm{mmol} / \mathrm{L})$ & $140(139,142)$ \\
Serum zinc concentration $(\mu \mathrm{g} / \mathrm{dL})$ & $72.85(63.7,81.45)$ \\
BTR & $5.63(4.2375,6.65)$ \\
FIB-4 index & $2.39(1.60,4.07)$ \\
APRI & $0.52(0.33,1.15)$ \\
\hline
\end{tabular}

Data are expressed as median value (interquartile range). Abbreviations: $\mathrm{HBV}$, hepatitis B virus; $\mathrm{HCV}$, hepatitis $\mathrm{C}$ virus; NBNC, non-B and non-C; LC, liver cirrhosis; AST, aspartate aminotransferase; ALT, alanine aminotransferase; ALP, alkaline phosphatase; GGT, gamma-glutamyltransferase; eGFR, estimated glomerular filtration rate; NSGP, National Glycohemoglobin Standardization Program; BTR, branched-chain amino acid ratio; APRI, AST to platelet ratio index. 

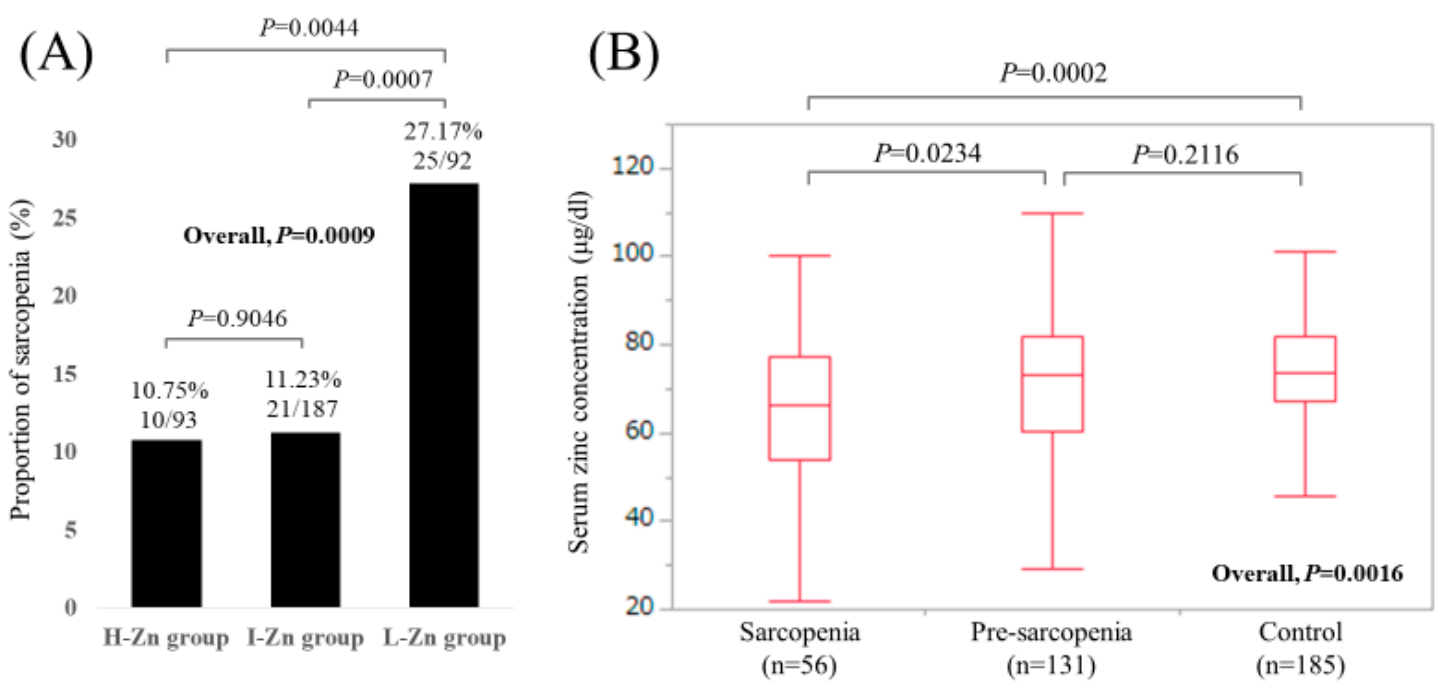

Figure 2. (A) The proportions of sarcopenia in the High-Zn, Intermediate- $Z n$, and Low-Zn groups. (B) Boxplots of serum $\mathrm{Zn}$ concentration in the High-Zn, Intermediate-Zn, and Low-Zn groups. The median (IQR) serum $\mathrm{Zn}$ concentrations in patients with sarcopenia, pre-sarcopenia, and control were $66.35(54.05,77.425) \mu \mathrm{g} / \mathrm{dL}, 73.1(60.4,82.1) \mu \mathrm{g} / \mathrm{dL}$, and $73.8(67.2,81.85) \mu \mathrm{g} / \mathrm{dL}$, respectively.

\subsection{Analyses According to the LC Status}

LC and non-LC were identified in 147 patients (39.5\%) and 225 patients $(60.5 \%)$ in the current analysis. The median (IQR) serum Zn concentration for LC cases $(63.8(52.7,74.4) \mu \mathrm{g} / \mathrm{dL})$ was significantly lower than that for non-LC cases $(75.8(70.45,84.45) \mu \mathrm{g} / \mathrm{dL})(P<0.0001)$ (Figure 3$)$. One-hundred and twenty-four LC patients $(84.3 \%)$ and 137 non-LC patients $(60.9 \%)$ had hypozincemia.

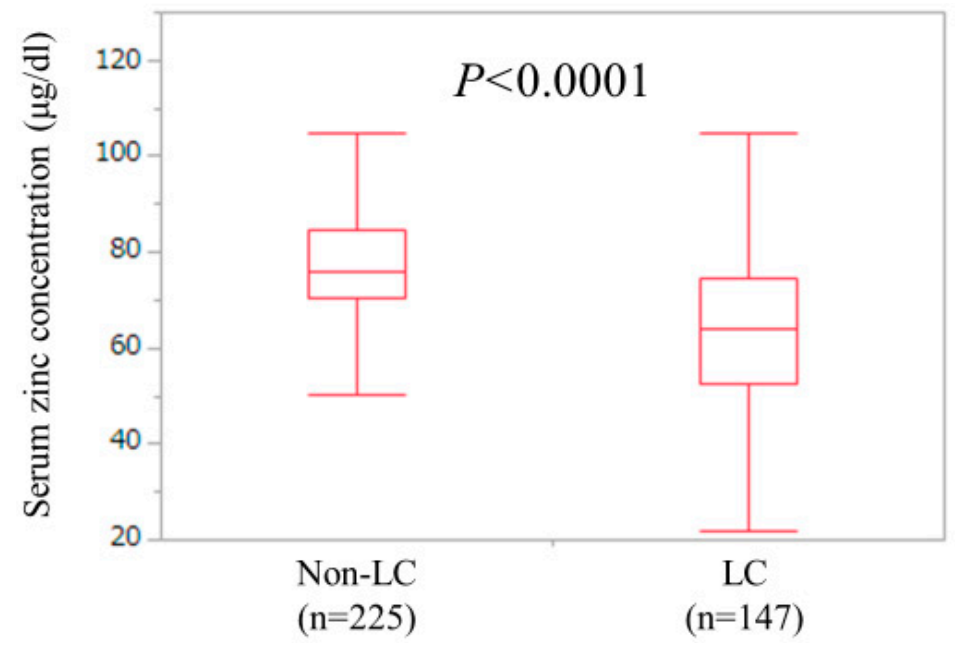

Figure 3. Serum Zn concentrations in LC $(n=147)$ and non-LC $(n=225)$ patients. The median (IQR) serum $\mathrm{Zn}$ concentration for LC cases $(63.8(52.7,74.4) \mu \mathrm{g} / \mathrm{dL})$ was significantly lower than that for non-LC cases $(75.8(70.45,84.45) \mu \mathrm{g} / \mathrm{dL})(P<0.0001)$. 
In LC patients, there were 29 (19.7\%), 56 (38.1\%), and 62 (42.2\%) patients with sarcopenia, pre-sarcopenia, and control, respectively. The median (IQR) serum Zn concentrations in LC patients with sarcopenia, pre-sarcopenia, and control were $55.7(43.15,61.4) \mu \mathrm{g} / \mathrm{dL}, 64.6(51.55,77.325) \mu \mathrm{g} / \mathrm{dL}$, and $66.4(58.45,74.175) \mu \mathrm{g} / \mathrm{dL}$, respectively ( $P$ values: $P=0.0516$ (sarcopenia vs. pre-sarcopenia), $P=0.4142$ (pre-sarcopenia vs. control), $P=0.0004$ (sarcopenia vs. control), overall $P$ value $=0.0055$ ) (Figure 4A).

In non-LC patients, there were $27(12.0 \%), 75(33.3 \%)$, and $123(54.7 \%)$ patients with sarcopenia, pre-sarcopenia, and control, respectively. The median (IQR) serum Zn concentrations in non-LC patients with sarcopenia, pre-sarcopenia, and control were $73.9(66.9,81.9) \mu \mathrm{g} / \mathrm{dL}, 75.4(69.0,86.0)$ $\mu \mathrm{g} / \mathrm{dL}$, and $76.5(71.2,84.3) \mu \mathrm{g} / \mathrm{dL}$, respectively ( $P$ values: $P=0.5069$ (sarcopenia vs. pre-sarcopenia), $P=0.5152$ (pre-sarcopenia vs. control), $P=0.1582$ (sarcopenia vs. control), overall $P$ value $=0.3125$ ) (Figure 4B).
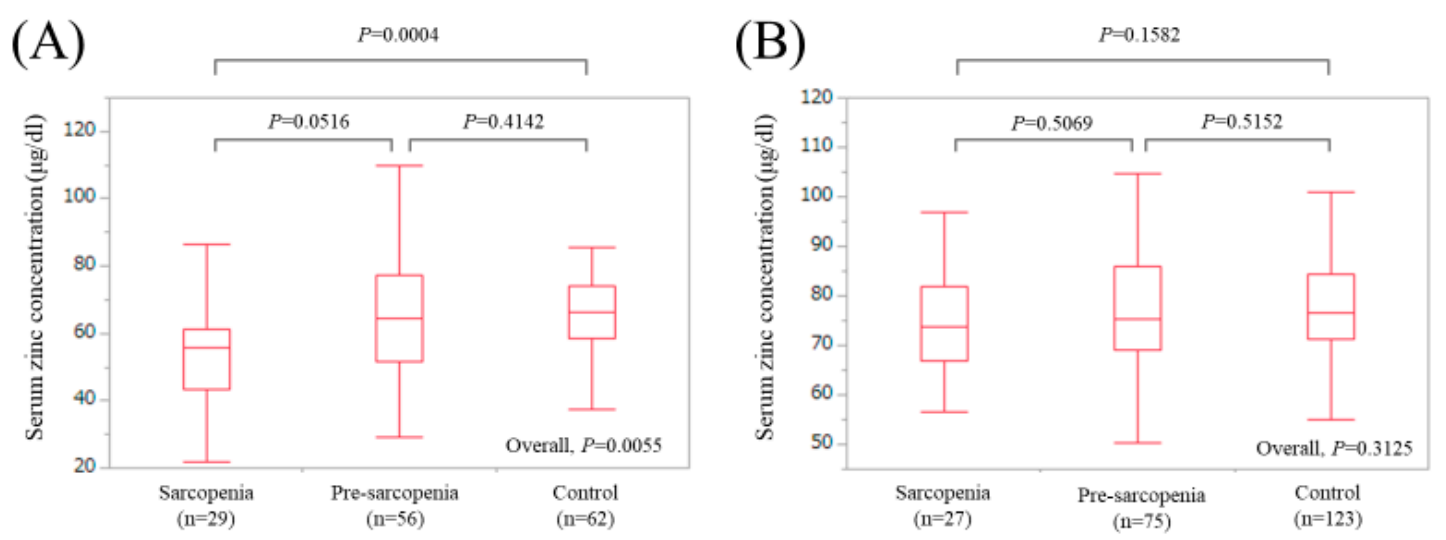

Figure 4. Boxplots of serum Zn concentration in the High-Zn, Intermediate-Zn, and Low-Zn groups in patients with LC (A) and non-LC (B). In LC patients, the median (IQR) serum Zn concentrations in sarcopenia, pre-sarcopenia, and control were $55.7(43.15,61.4) \mu \mathrm{g} / \mathrm{dL}, 64.6(51.55,77.325) \mu \mathrm{g} / \mathrm{dL}$, and $66.4(58.45,74.175) \mu \mathrm{g} / \mathrm{dL}$, respectively. In non-LC patients, the median (IQR) serum Zn concentrations in sarcopenia, pre-sarcopenia, and control were $73.9(66.9,81.9) \mu \mathrm{g} / \mathrm{dL}, 75.4(69.0,86.0) \mu \mathrm{g} / \mathrm{dL}$, and $76.5(71.2,84.3) \mu \mathrm{g} / \mathrm{dL}$, respectively.

\subsection{Uni-and Multivariate Analyses of Factors Associated with the Presence of Sarcopenia for All Cases $(n=372)$}

In all cases, univariate analysis identified nine factors to be significantly associated with the presence of sarcopenia: age $(P<0.0001)$, body mass index, (BMI, $P<0.0001)$, presence of LC $(P=0.0416)$, total bilirubin $(P=0.0276)$, serum albumin $(P=0.0008)$, alkaline phosphatase (ALP, $P=0.0143$ ), estimated glomerular filtration rate (eGFR, $P=0.0178)$, serum sodium $(P=0.0164)$, and our classification of serum zinc concentration $(P=0.0009)$ (Table 2$)$. Multivariate analysis for the nine factors showed that age $(P=0.0005)$, BMI $(P=0.0003)$, serum albumin $(P=0.0011)$, and $\mathrm{L}-\mathrm{Zn}$ group $(P=0.0236$, I-Zn group as a reference) were found to be significant factors linked to the presence of sarcopenia (Table 3 ). Hazard ratios (HRs) and 95\% confidence intervals (CIs) for these variables were listed in Table 3. 
Table 2. Univariate analyses of factors associated with the presence of sarcopenia for all cases $(n=372)$.

\begin{tabular}{cccc}
\hline Variables & Sarcopenia $(\boldsymbol{n}=\mathbf{5 6})$ & Non-Sarcopenia $(\boldsymbol{n}=\mathbf{3 1 6})$ & $\boldsymbol{P}$ Value \\
\hline Age (years) & $72.5(67.25,76.75)$ & $63(52,70)$ & $<0.0001$ \\
Gender, male/female & $27 / 29$ & $144 / 172$ & 0.7144 \\
HBV /HCV /HBV and HCV/NBNC & $6 / 31 / 2 / 17$ & $47 / 193 / 6 / 70$ & 0.4195 \\
Body mass index (kg/m $\left.{ }^{2}\right)$ & $20.6(19.7,22.7)$ & $22.95(20.7,26)$ & $<0.0001$ \\
Presence of LC, yes/no & $29 / 27$ & $118 / 198$ & 0.0416 \\
Total bilirubin $(\mathrm{mg} / \mathrm{dL})$ & $0.7(0.5,0.95)$ & $0.8(0.6,1.1)$ & 0.0276 \\
Serum albumin (g/dL) & $3.95(3.225,4.3)$ & $4.2(3.8,4.5)$ & 0.0008 \\
Prothrombin time (\%) & $85.3(74.45,98.825)$ & $88.7(78.45,96.475)$ & 0.6971 \\
Platelet count $\left(\times 10^{4} / \mathrm{mm}^{3}\right)$ & $15.1(10.2,18.6)$ & $16.75(11.525,20.8)$ & 0.2303 \\
AST (IU/L) & $32(22,49)$ & $27(21,40.75)$ & 0.3978 \\
ALT (IU/L) & $26(15,42)$ & $23(16,40)$ & 0.8374 \\
ALP (IU/L) & $287(206,372)$ & $237(192,301)$ & 0.0143 \\
GGT (IU/L) & $30(18.5,52)$ & $28(17,50)$ & 0.5899 \\
Total cholesterol (mg/dL) & $179(142,212)$ & $179(154,205.75)$ & 0.3933 \\
eGFR (mL/min/1.73 m $\left.{ }^{2}\right)$ & $76(57,92)$ & $83(71,96.75)$ & 0.0178 \\
Serum sodium (mmol/L) & $140(138,141)$ & $140(139,142)$ & 0.0164 \\
HbA1c (NGSP) & $5.85(5.2,6.1)$ & $5.6(5.4,6.0)$ & 0.4177 \\
Serum zinc concentration & $10 / 21 / 25$ & $83 / 166 / 67$ & 0.0009 \\
(High/Intermediate/Low) & $5.19(3.6,7.21)$ & $5.64(4.34,6.625)$ & 0.5460 \\
BTR & $3.09(2.15,5.09)$ & $2.28(1.49,4.01)$ & 0.1409 \\
FIB-4 index & $0.61(0.35,1.42)$ & $0.51(0.32,1.09)$ & 0.8192 \\
APRI &
\end{tabular}

Data are expressed as median value (interquartile range). Abbreviations: $\mathrm{HBV}$, hepatitis $\mathrm{B}$ virus; $\mathrm{HCV}$, hepatitis $\mathrm{C}$ virus; NBNC, non-B and non-C; LC, liver cirrhosis; AST, aspartate aminotransferase; ALT, alanine aminotransferase; ALP, alkaline phosphatase; GGT, gamma-glutamyltransferase; eGFR, estimated glomerular filtration rate; NSGP, National Glycohemoglobin Standardization Program; BTR, branched-chain amino acid ratio.

Table 3. Multivariate analyses of factors linked to the presence of sarcopenia for all cases.

\begin{tabular}{cccc}
\hline & \multicolumn{3}{c}{ Multivariate Analysis } \\
\cline { 2 - 4 } & Hazard Ratio & 95\% CI & P Value \\
\hline Age (per one year) & 1.075 & $1.032-1.120$ & 0.0005 \\
BMI (per one kg/m ${ }^{2}$ ) & 0.790 & $0.695-0.898$ & 0.0003 \\
Presence of LC & 1.541 & $0.645-3.690$ & 0.3306 \\
Serum albumin (per one g/dL) & 0.208 & $0.081-0.533$ & 0.0011 \\
Total bilirubin (per one mg/dL) & 0.439 & $0.176-1.093$ & 0.0769 \\
ALP (per one IU/L) & 1.002 & $0.999-1.005$ & 0.1273 \\
eGFR (per one mL/min/1.73 m ${ }^{2}$ ) & 1.001 & $0.985-1.018$ & 0.8715 \\
Serum sodium (per one mmol/L) & 0.899 & $0.791-1.022$ & 0.1061 \\
Classification of serum zinc level & & & \\
Intermediate-Zn group & 1.000 & Reference & \\
High-Zn group & 1.812 & $0.722-4.545$ & 0.2053 \\
Low-Zn group & 3.030 & $1.160-7.937$ & 0.0236 \\
\hline
\end{tabular}

Abbreviations: BMI, body mass index; LC, liver cirrhosis; ALP, alkaline phosphatase; eGFR, estimated glomerular filtration rate; $\mathrm{Zn}$, zinc; $\mathrm{CI}$, confidence interval.

\subsection{Uni- and Multivariate Analyses of Factors Associated with the Presence of Sarcopenia for LC Cases ( $n=147)$}

In LC-cases, univariate analysis identified four factors to be significantly associated with the presence of sarcopenia: age $(P=0.0026)$, BMI $(P=0.0010)$, serum albumin $(P=0.0035)$, and our classification of serum zinc concentration $(P=0.0016)$ (Table 4$)$. Multivariate analysis for the four factors showed that age $(P=0.0363), \mathrm{BMI}(P=0.0014)$, and L-Zn group $(P=0.0082, \mathrm{I}-\mathrm{Zn}$ group as a reference) were found to be significant factors linked to the presence of sarcopenia (Table 5). HRs and 95\% CIs for these variables were listed in Table 5. 
Table 4. Univariate analyses of factors associated with the presence of sarcopenia for LC cases $(n=147)$.

\begin{tabular}{cccc}
\hline Variables & Sarcopenia $(\boldsymbol{n = 2 9 )}$ & Non-Sarcopenia $(\boldsymbol{n}=\mathbf{1 1 8})$ & $\boldsymbol{P}$ Value \\
\hline Age (years) & $71(67,76)$ & $67(59,72)$ & 0.0026 \\
Gender, male/female & $15 / 54$ & $65 / 53$ & 0.7448 \\
HBV /HCV/HBV and HCV/NBNC & $4 / 15 / 1 / 9$ & $15 / 73 / 0 / 30$ & 0.1897 \\
Body mass index $\left(\mathrm{kg} / \mathrm{m}^{2}\right)$ & $20.4(19.8,23.0)$ & $23.05(20.7,26.275)$ & 0.0010 \\
Total bilirubin $(\mathrm{mg} / \mathrm{dL})$ & $0.8(0.6,1.2)$ & $1.1(0.8,1.625)$ & 0.0582 \\
Serum albumin $(\mathrm{g} / \mathrm{dL})$ & $3.4(2.95,3.9)$ & $3.8(3.4,4.125)$ & 0.0035 \\
Prothrombin time $(\%)$ & $81.9(58.55,87.95)$ & $78.25(63.175,88.3)$ & 0.8211 \\
Platelet count $\left(\times 10^{4} / \mathrm{mm}^{3}\right)$ & $10.4(8.05,15.7)$ & $10.85(7.4,14.525)$ & 0.6432 \\
AST (IU/L) & $45(29.75,56.75)$ & $37.5(25,53)$ & 0.2028 \\
ALT (IU/L) & $32.5(21.75,48)$ & $28.5(17.75,43.25)$ & 0.3652 \\
ALP (IU/L) & $339.5(234,499.75)$ & $264(219,402)$ & 0.1226 \\
GGT (IU/L) & $41(22,74)$ & $37(21.5,67)$ & 0.6964 \\
Total cholesterol (mg/dL) & $144(120.75,188.5)$ & $155.5(137,180)$ & 0.4466 \\
eGFR (mL/min/1.73 m $\left.{ }^{2}\right)$ & $80(66,93.75)$ & $82(68,99)$ & 0.4683 \\
Serum sodium (mmol/L) & $139(137,140)$ & $140(138,142)$ & 0.0574 \\
HbA1c (NGSP) & $5.2(5.0,6.0)$ & $5.6(5.2,6.15)$ & 0.3641 \\
Serum zinc classification & $2 / 4 / 23$ & $15 / 53 / 50$ & 0.0016 \\
High/Intermediate/Low & $3.7(2.9875,4.935)$ & $4.245(3.2675,5.64)$ & 0.1690 \\
BTR & $4.83(3.14,7.56)$ & $4.27(2.68,6.80)$ & 0.9641 \\
FIB-4 index & $1.29(0.70,1.95)$ & $1.08(0.60,1.91)$ & 0.6814 \\
APRI &
\end{tabular}

Data are expressed as median value (interquartile range). Abbreviation: $\mathrm{HBV}$, hepatitis $\mathrm{B}$ virus; $\mathrm{HCV}$, hepatitis $\mathrm{C}$ virus; NBNC, non-B and non-C; LC, liver cirrhosis; AST, aspartate aminotransferase; ALT, alanine aminotransferase; ALP, alkaline phosphatase; GGT, gamma-glutamyltransferase; eGFR, estimated glomerular filtration rate; NSGP, National Glycohemoglobin Standardization Program; BTR, branched-chain amino acid ratio.

Table 5. Multivariate analyses of factors linked to the presence of sarcopenia for LC cases.

\begin{tabular}{cccc}
\hline & \multicolumn{3}{c}{ Multivariate Analysis } \\
\cline { 2 - 4 } & Hazard Ratio & $\mathbf{9 5 \%}$ CI & $\boldsymbol{P}$ Value \\
\hline Age (per one year) & 1.054 & $1.003-1.106$ & 0.0363 \\
BMI (per one kg/m $\mathrm{m}^{2}$ ) & 0.755 & $0.636-0.898$ & 0.0014 \\
Serum albumin (per one g/dL) & 0.377 & $0.121-1.520$ & 0.1890 \\
Classification of serum zinc level & & & \\
Intermediate-Zn group & 1.000 & Reference & \\
High-Zn group & 2.500 & $0.377-16.667$ & 0.3429 \\
Low-Zn group & 6.410 & $1.618-25.641$ & 0.0082 \\
\hline
\end{tabular}

Abbreviations: BMI, body mass index; Zn, zinc; CI, confidence interval.

3.5. Uni- and Multivariate Analyses of Factors Associated with the Presence of Sarcopenia for Non-LC Cases $(n=225)$

In non-LC cases, univariate analysis identified four factors to be significantly associated with the presence of sarcopenia: age $(P<0.0001)$, BMI $(P=0.0003)$, eGFR $(P=0.0063)$, and HbA1c $(P=0.0091)$ (Table 6). Multivariate analysis for the four factors showed that age $(P=0.0249)$ and BMI $(P=0.0021)$ were found to be significant factors linked to the presence of sarcopenia (Table 7). HRs and 95\% CIs for these variables were listed in Table 7. 
Table 6. Univariate analyses of factors associated with the presence of sarcopenia for non-LC cases $(n=225)$.

\begin{tabular}{cccc}
\hline Variables & Sarcopenia $(\boldsymbol{n}=\mathbf{2 7})$ & Non-Sarcopenia $(\boldsymbol{n}=\mathbf{1 9 8})$ & $\boldsymbol{P}$ Value \\
\hline Age (years) & $73(67,78)$ & $60(48.75,67)$ & $<0.0001$ \\
Gender, male/female & $12 / 15$ & $79 / 119$ & 0.6518 \\
HBV /HCV /HBV and HCV/NBNC & $2 / 16 / 1 / 8$ & $32 / 120 / 6 / 40$ & 0.5248 \\
Body mass index $\left(\mathrm{kg} / \mathrm{m}^{2}\right)$ & $20.9(19.3,22.3)$ & $22.9(20.675,25.725)$ & 0.0003 \\
Total bilirubin $(\mathrm{mg} / \mathrm{dL})$ & $0.6(0.5,0.7)$ & $0.8(0.6,1.0)$ & 0.0527 \\
Serum albumin $(\mathrm{g} / \mathrm{dL})$ & $4.2(4.0,4.5)$ & $4.3(4.1,4.5)$ & 0.1374 \\
Prothrombin time (\%) & $93.5(84.7,99)$ & $92.5(84.95,100.025)$ & 0.5236 \\
Platelet count $\left(\times 10^{4} / \mathrm{mm}^{3}\right)$ & $17.45(14.85,20.7)$ & $19.25(15.65,22.95)$ & 0.5282 \\
AST (IU/L) & $23(18,33)$ & $24(19,33)$ & 0.3645 \\
ALT (IU/L) & $15(12,32)$ & $20(15,35.25)$ & 0.3151 \\
ALP (IU/L) & $243(177,306)$ & $224.5(178.75,275.75)$ & 0.1149 \\
GGT (IU/L) & $25(15.75,42.5)$ & $23(15,44)$ & 0.9164 \\
Total cholesterol (mg/dL) & $195(165,218)$ & $193(170.75,219)$ & 0.8202 \\
eGFR (mL/min/1.73 m $\left.{ }^{2}\right)$ & $66(56,92)$ & $84(72,95.5)$ & 0.0063 \\
Serum sodium (mmol/L) & $140(138,142)$ & $141(139,142)$ & 0.3751 \\
HbA1c (NGSP) & $6.0(5.6,6.4)$ & $5.7(5.4,5.925)$ & 0.0091 \\
Serum zinc classification & $8 / 17 / 2$ & $68 / 113 / 17$ & 0.8444 \\
High/Intermediate/Low & $6.92(5.64,7.72)$ & $6.25(5.28,7.05)$ & 0.0544 \\
BTR & $2.13(1.64,2.86)$ & $1.73(1.13,2.47)$ & 0.1066 \\
FIB-4 index & $0.35(0.28,0.52)$ & $0.36(0.29,0.63)$ & 0.3683 \\
APRI & & &
\end{tabular}

Table 7. Multivariate analyses of factors linked to the presence of sarcopenia for non-LC cases.

\begin{tabular}{cccc}
\hline & \multicolumn{3}{c}{ Multivariate Analysis } \\
\cline { 2 - 4 } & Hazard Ratio & $\mathbf{9 5 \%}$ CI & $\boldsymbol{P}$ Value \\
\hline Age (per one year) & 1.071 & $1.004-1.142$ & 0.0249 \\
BMI (per one $\mathrm{kg} / \mathrm{m}^{2}$ ) & 0.746 & $0.602-0.923$ & 0.0021 \\
eGFR (per one $\mathrm{mL} / \mathrm{min} / 1.73 \mathrm{~m}^{2}$ ) & 0.985 & $0.955-1.015$ & 0.3257 \\
HbA1c (per one) & 1.280 & $0.727-5.376$ & 0.2127 \\
\hline
\end{tabular}

Abbreviations: BMI, body mass index; eGFR, estimated glomerular filtration rate; $\mathrm{CI}$, confidence interval.

\subsection{Correlation between Serum Zinc Concentration and Baseline Characteristics}

Correlation coefficients and $P$ values between serum zinc concentration and baseline characteristics were listed in Table 8. Serum albumin level had the strongest positive correlation with serum $\mathrm{Zn}$ concentration $(r=0.654, P<0.0001)$ followed by branched-chain amino acid to tyrosine ratio $(r=0.496, P<0.0001)$, while FIB-4 index had the strongest negative correlation with serum $\mathrm{Zn}$ concentration $(r=-0.360, P<0.0001)$ followed by total bilirubin $(r=-0.355, P<0.0001)$. Multivariate analysis of factors significantly correlated with serum $\mathrm{Zn}$ concentration revealed that only serum albumin level was a significant factor linked to serum $\mathrm{Zn}$ concentration $(P<0.0001)$. 
Table 8. Relationship between serum zinc concentration and baseline characteristics.

\begin{tabular}{ccc}
\hline & $\boldsymbol{r}$ & $\boldsymbol{P}$ Value \\
\hline Age & -0.186 & 0.0003 \\
Body mass index & -0.032 & 0.5424 \\
Total bilirubin & -0.355 & $<0.0001$ \\
Serum albumin & 0.654 & $<0.0001$ \\
Prothrombin time & 0.395 & $<0.0001$ \\
Platelets & 0.295 & $<0.0001$ \\
Serum sodium & 0.249 & 0.8923 \\
eGFR & -0.020 & 0.7029 \\
Total cholesterol & 0.266 & $<0.0001$ \\
AST & -0.230 & $<0.0001$ \\
ALT & -0.065 & 0.2126 \\
ALP & -0.245 & $<0.0001$ \\
GGT & -0.206 & $<0.0001$ \\
HbA1c (NSGP) & 0.133 & 0.0242 \\
BTR & 0.496 & $<0.0001$ \\
FIB-4 index & -0.360 & $<0.0001$ \\
APRI & -0.289 & $<0.0001$ \\
\hline
\end{tabular}

Abbreviations: eGFR, estimated glomerular filtration rate; AST, aspartate aminotransferase; ALT, alanine aminotransferase; ALP, alkaline phosphatase; GGT, gamma-glutamyltransferase; NSGP, National Glycohemoglobin Standardization Program; BTR, branched-chain amino acid ratio; APRI, AST to platelet ratio index.

\section{Discussion}

Chronic liver injury results in the impaired Zn homeostasis and eventually Zn deficiency, and most CLD patients have Zn deficiency [3-5,10,13,14,32]. Zn deficiency can present numerous symptoms, which can be associated with decreased QOL and worse clinical outcomes [3,5,33]. However, as mentioned earlier, there is little data currently available regarding relationship between serum $\mathrm{Zn}$ concentration and sarcopenia in CLDs. To clarify these issues is clinically of great importance due to the increasing interest for sarcopenia in CLDs these days. To the best of our knowledge, this is the first study elucidating the association between serum $\mathrm{Zn}$ level and sarcopenia in CLDs using large cohort $(n=372)$.

First of all, the validity of our classification of H-Zn, I-Zn, and L-Zn groups needs discussion. As mentioned above, CLD patients have tendency for lower serum $\mathrm{Zn}$ levels and only 111 of our analyzed subjects $(29.8 \%$ ) had normal serum $\mathrm{Zn}$ value (reference range, $80 \mu \mathrm{g} / \mathrm{dL} \leq$ serum $\mathrm{Zn}$ concentration $\leq 130 \mu \mathrm{g} / \mathrm{dL}$ in our institution) [3,5,7]. Therefore, we classified them into three groups based on quartiles in our cohort for the appropriate analysis and investigated the impact of serum $\mathrm{Zn}$ concentration on sarcopenia. In our analysis, the proportion of sarcopenia in the L-Zn group was significantly higher than that in the I-Zn group or the H-Zn group. Additionally, our multivariate analyses revealed that $\mathrm{L}-\mathrm{Zn}$ was an independent predictor linked to the presence of sarcopenia for all cases and LC cases. These results suggest the clinical significance of serum $\mathrm{Zn}$ concentration for sarcopenia in CLD patients, even considering the non-significant relation between serum $\mathrm{Zn}$ concentration and sarcopenia in non-LC cases. Zn deficiency induces a number of physiological problems, which can be associated with sarcopenia [34]. In CLD patients, close monitoring for serum $\mathrm{Zn}$ concentration may be required for identifying sarcopenic subjects. While patients with pre-sarcopenia had similar serum Zn concentration to those with control for all cases, LC cases, and non-LC cases. Reviewing these results, sarcopenia staging (i.e., distinguishing between sarcopenia and pre-sarcopenia) seems to be an important strategy for CLD patients. A recent study reported that a stepwise increase of the proportion of fallers according to the severity of sarcopenia was observed in older populations, which was in line with our current results [35]. On the other hand, appropriate timing of Zn supplementation therapy should also be considered in CLD patients from the clinicians' perspective. In addition, whether Zn supplementation therapy in sarcopenic CLD patients can reverse sarcopenia needs to be clarified in future studies. 
In comparison between L-Zn group and $\mathrm{H}-\mathrm{Zn}$ group, the impact on sarcopenia was not prominent in the multivariate analysis for all cases ( $\mathrm{HR}=1.672, P=0.3881, \mathrm{H}-\mathrm{Zn}$ as a reference). Although the reasons for these are unclear, maintaining serum $\mathrm{Zn}$ concentration in a certain range may be essential for avoiding sarcopenia in CLD patients.

Serum albumin level had the strongest positive correlation with serum $\mathrm{Zn}$ concentration $(r=0.654$, $P<0.0001)$ and it was an independent predictor associated with serum $\mathrm{Zn}$ concentration in the multivariate analysis, while FIB-4 index had the strongest negative correlation with serum $\mathrm{Zn}$ concentration $(r=-0.360, P<0.0001)$ in our data. Because protein synthesis ability reflects serum $\mathrm{Zn}$ concentration, these results are not so surprising $[3,5,7]$. More importantly, age was correlated inversely with serum $\mathrm{Zn}$ concentration, although the $r$ value was not impressive $(r=-0.186, P=0.0003)$. In aging process, a lot of mediators can be associated with inflammation and oxidative stress, and imbalance of $\mathrm{Zn}$ homeostasis is a common hallmark of aging [36-38]. The high prevalence of hypozincemia in our LC patients (84.3\%) may be partly attributed to the higher age of our LC patients (median age $=68.0$ years), as well as protein synthesis inability and other metabolic disorders $[3,5,7]$. On the other hand, clinicians should be aware that even in non-LC patients, a considerable number of patients with hypozincemia are present $(60.9 \%$ in our non-LC patients).

Both age and BMI were independent predictors for all cases, LC cases, and non-LC cases in our multivariate analyses. CLD patients appears to suffer from sarcopenia based on the following two types of sarcopenia: aging-related sarcopenia (primary sarcopenia) and CLD specific abnormalities-related sarcopenia (secondary sarcopenia) [18]. Our current results may be attributed to the increase of aging CLD patients in our country [39-41]. As CLD patients age, the incidence of physical performance limitation will increase and sarcopenia may be an inevitable consequence with aging [42]. While lower BMI was shown to have strong influence on sarcopenia in our CLD patients, the impact of obesity on sarcopenia (sarcopenic obesity) cannot be ignored, since there were only 3 patients $(0.8 \%)$ with BMI $>35 \mathrm{~kg} / \mathrm{m}^{2}$ in our study subjects $[43,44]$.

We acknowledge several limitations to this study. First, the study was a retrospective single-center observational study without non-CLD patients as a control group. Second, GpS and serum Zn concentration can vary depending on patient daily life activities or dietary habits. Third, patients with massive ascites potentially involved in liver disease-related sarcopenia were excluded because of the lack of reliability in BIA, creating bias. This was the major limitation for the evaluation of muscle mass using BIA compared with using computed tomography or magnetic resonance imaging, however, BIA may be cost-effective. Fourth, data for other trace elements such as calcium, iron, phosphorus, magnesium, and selenium were not included in this study, leading to bias. Fifth, due to the small number of cases with sarcopenic obesity in our study, the relationship between serum $\mathrm{Zn}$ concentration and sarcopenic obesity remains unknown. Finally, it was uncertain as to whether sarcopenia caused Zn deficiency or whether Zn deficiency caused sarcopenia in this cross-sectional study. Consequently, caution should be exercised for the interpretation of the current study data and larger prospective studies will be needed to confirm these results. Despite these limitations, our study results denoted that Zn deficiency in CLDs was closely associated with sarcopenia.

\section{Conclusions}

In conclusion, Zn deficiency can be an independent predictor for sarcopenia in patients with CLDs.

Author Contributions: Data curation, K.Y., Y.I., Y.S., K.K., N.I. (Naoto Ikeda), T.T., N.A., R.T., K.H., (N.I.) Noriko Ishii, Y.Y., T.N., and H.I.; Formal analysis, H.N.; Supervision and S.N.; Writing-original draft, H.N.; Writing-review and editing, H.N. and H.E.

Acknowledgments: The authors gratefully thank all medical staff in our nutritional guidance room for their help with data collection. This work was partly granted by Hyogo Innovative Challenge, Hyogo College of Medicine, Japan.

Conflicts of Interest: The authors declare no conflicts of interest. 


\section{References}

1. Alker, W.; Haase, H. Zinc and Sepsis. Nutrients 2018, 10, 976. [CrossRef] [PubMed]

2. Costello, L.C.; Franklin, R.B. Decreased zinc in the development and progression of malignancy: An important common relationship and potential for prevention and treatment of carcinomas. Expert Opin. Ther. Targets 2017, 21, 51-66. [CrossRef] [PubMed]

3. Himoto, T.; Masaki, T. Associations between Zinc Deficiency and Metabolic Abnormalities in Patients with Chronic Liver Disease. Nutrients 2018, 10, 88. [CrossRef] [PubMed]

4. Liuzzi, J.P.; Guo, L.; Yoo, C.; Stewart, T.S. Zinc and autophagy. Biometals 2014, 27, 1087-1096. [CrossRef] [PubMed]

5. Grüngreiff, K.; Reinhold, D.; Wedemeyer, H. The role of zinc in liver cirrhosis. Ann. Hepatol. 2016, 15, 7-16. [CrossRef] [PubMed]

6. Vidot, H.; Carey, S.; Allman-Farinelli, M.; Shackel, N. Systematic review: The treatment of muscle cramps in patients with cirrhosis. Aliment. Pharmacol. Ther. 2014, 40, 221-232. [CrossRef] [PubMed]

7. Koop, A.H.; Mousa, O.Y.; Pham, L.E.; Corral-Hurtado, J.E.; Pungpapong, S.; Keaveny, A.P. An Argument for Vitamin D, A, and Zinc Monitoring in Cirrhosis. Ann. Hepatol. 2018, 17, 920-932. [CrossRef] [PubMed]

8. Martínez-Peinado, M.; Rueda-Robles, A.; Nogueras-López, F.; Villalón-Mir, M.; Oliveras-López, M.J.; Navarro-Alarcón, M. Serum zinc and copper concentrations and ratios in cirrhotic patients: Correlation with severity index. Nutr. Hosp. 2018, 35, 627-632. [CrossRef] [PubMed]

9. Skalny, A.V.; Skalnaya, M.G.; Grabeklis, A.R.; Skalnaya, A.A.; Tinkov, A.A. Zinc deficiency as a mediator of toxic effects of alcohol abuse. Eur. J. Nutr. 2018, 57, 2313-2322. [CrossRef] [PubMed]

10. Grüngreiff, K. Branched Amino Acids and Zinc in the Nutrition of Liver Cirrhosis. J. Clin. Exp. Hepatol. 2018, 8, 480-483. [CrossRef] [PubMed]

11. Hosui, A.; Kimura, E.; Abe, S.; Tanimoto, T.; Onishi, K.; Kusumoto, Y.; Sueyoshi, Y.; Matsumoto, K.; Hirao, M.; Yamada, T.; et al. Long-Term Zinc Supplementation Improves Liver Function and Decreases the Risk of Developing Hepatocellular Carcinoma. Nutrients 2018, 10, 1955. [CrossRef] [PubMed]

12. Grüngreiff, K.; Presser, H.J.; Franke, D.; Lössner, B.; Kleine, F.D. Correlations between zinc, amino acids and ammonia in liver cirrhosis. Z. Gastroenteriol. 1989, 27, 731-735.

13. Katayama, K.; Saito, M.; Kawaguchi, T.; Endo, R.; Sawara, K.; Nishiguchi, S.; Kato, A.; Kohgo, H.; Suzuki, K.; Sakaida, I.; et al. Effect of zinc on liver cirrhosis with hyperammonemia: A preliminary randomized, placebo-controlled double-blind trial. Nutrition 2014, 30, 1409-1414. [CrossRef] [PubMed]

14. Sengupta, S.; Wroblewski, K.; Aronsohn, A.; Reau, N.; Reddy, K.G.; Jensen, D.; Te, H. Screening for Zinc Deficiency in Patients with Cirrhosis: When Should We Start? Dig. Dis. Sci. 2015, 60, 3130-3135. [CrossRef] [PubMed]

15. Kazunari, I.; Hirayuki, E.; Shuhei, N.; Nobuhiro, A.; Yoshiyuki, S.; Yoshinori, I.; Hironori, T.; Naoto, I.; Tomoyuki, T.; Masaki, S.; et al. Serum zinc value in patients with hepatitis virus-related chronic liver disease: Association with the histological degree of liver fibrosis and with the severity of varices in compensated cirrhosis. J. Clin. Biochem. Nutr. 2014, 55, 147-152.

16. Kim, G.; Kang, S.H.; Kim, M.Y.; Baik, S.K. Prognostic value of sarcopenia in patients with liver cirrhosis: A systematic review and meta-analysis. PLoS ONE 2017, 12, e0186990. [CrossRef] [PubMed]

17. Tsekoura, M.; Kastrinis, A.; Katsoulaki, M.; Billis, E.; Gliatis, J. Sarcopenia and Its Impact on Quality of Life. Adv. Exp. Med. Biol. 2017, 987, 213-218. [PubMed]

18. Nishikawa, H.; Shiraki, M.; Hiramatsu, A.; Moriya, K.; Hino, K.; Nishiguchi, S. Japan Society of Hepatology guidelines for sarcopenia in liver disease (1st edition): Recommendation from the working group for creation of sarcopenia assessment criteria. Hepatol. Res. 2016, 46, 951-963. [CrossRef] [PubMed]

19. Montano-Loza, A.J. Clinical relevance of sarcopenia in patients with cirrhosis. World J. Gastroenterol. 2014, 20, 8061-8071. [CrossRef] [PubMed]

20. Cruz-Jentoft, A.J.; Landi, F.; Schneider, S.M.; Zúñiga, C.; Arai, H.; Boirie, Y.; Chen, L.K.; Fielding, R.A.; Martin, F.C.; Michel, J.P.; et al. Prevalence of and interventions for sarcopenia in ageing adults: A systematic review. Report of the International Sarcopenia Initiative (EWGSOP and IWGS). Age Ageing 2014, 43, 748-759. [CrossRef] [PubMed] 
21. Sinclair, M.; Gow, P.J.; Grossmann, M.; Angus, P.W. Review article: Sarcopenia in cirrhosis-aetiology, implications and potential therapeutic interventions. Aliment. Pharmacol. Ther. 2016, 43, 765-777. [CrossRef] [PubMed]

22. Chen, L.K.; Liu, L.K.; Woo, J.; Assantachai, P.; Auyeung, T.W.; Bahyah, K.S.; Chou, M.Y.; Chen, L.Y.; Hsu, P.S.; Krairit, O.; et al. Sarcopenia in Asia: Consensus Report of the Asian Working Group for Sarcopenia. J. Am. Med. Dir. Assoc. 2014, 15, 95-101. [CrossRef] [PubMed]

23. Nishikawa, H.; Enomoto, H.; Ishii, A.; Iwata, Y.; Miyamoto, Y.; Ishii, N.; Yuri, Y.; Hasegawa, K.; Nakano, C.; Nishimura, T.; et al. Elevated serum myostatin level is associated with worse survival in patients with liver cirrhosis. J. Cachexia Sarcopenia Muscle 2017, 8, 915-925. [CrossRef] [PubMed]

24. Nishikawa, H.; Enomoto, H.; Ishii, A.; Iwata, Y.; Miyamoto, Y.; Ishii, N.; Yuri, Y.; Takata, R.; Hasegawa, K.; Nakano, C.; et al. Development of a simple predictive model for decreased skeletal muscle mass in patients with compensated chronic liver disease. Hepatol. Res. 2017, 47, 1223-1234. [CrossRef] [PubMed]

25. Shirai, H.; Kaido, T.; Hamaguchi, Y.; Kobayashi, A.; Okumura, S.; Yao, S.; Yagi, S.; Kamo, N.; Taura, K.; Okajima, H.; et al. Preoperative Low Muscle Mass and Low Muscle Quality Negatively Impact on Pulmonary Function in Patients Undergoing Hepatectomy for Hepatocellular Carcinoma. Liver Cancer 2018, 7, 76-89. [CrossRef] [PubMed]

26. De Bandt, J.P.; Jegatheesan, P.; Tennoune-El-Hafaia, N. Muscle Loss in Chronic Liver Diseases: The Example of Nonalcoholic Liver Disease. Nutrients 2018, 10, 1195. [CrossRef] [PubMed]

27. Chang, K.V.; Chen, J.D.; Wu, W.T.; Huang, K.C.; Hsu, C.T.; Han, D.S. Association between Loss of Skeletal Muscle Mass and Mortality and Tumor Recurrence in Hepatocellular Carcinoma: A Systematic Review and Meta-Analysis. Liver Cancer 2018, 7, 90-103. [CrossRef] [PubMed]

28. Tachi, Y.; Kozuka, A.; Hirai, T.; Ishizu, Y.; Honda, T.; Kuzuya, T.; Hayashi, K.; Ishigami, M.; Goto, H. Impact of myosteatosis on skeletal muscle volume loss in patients with chronic liver disease. J. Gastroenterol. Hepatol. 2018. [CrossRef] [PubMed]

29. Laube, R.; Wang, H.; Park, L.; Heyman, J.K.; Vidot, H.; Majumdar, A.; Strasser, S.I.; McCaughan, G.W.; Liu, K. Frailty in advanced liver disease. Liver Int. 2018, 38, 2117-2128. [CrossRef] [PubMed]

30. Kahn, J.; Wagner, D.; Homfeld, N.; Müller, H.; Kniepeiss, D.; Schemmer, P. Both sarcopenia and frailty determine suitability of patients for liver transplantation-A systematic review and meta-analysis of the literature. Clin. Transplant. 2018, 32, e13226. [CrossRef] [PubMed]

31. Bhanji, R.A.; Narayanan, P.; Allen, A.M.; Malhi, H.; Watt, K.D. Sarcopenia in hiding: The risk and consequence of underestimating muscle dysfunction in nonalcoholic steatohepatitis. Hepatology 2017, 66, 2055-2065. [CrossRef] [PubMed]

32. Grüngreiff, K. Zinc in liver disease. J. Trace Elem. Exp. Med. 2002, 15, 67-78. [CrossRef]

33. Kawaguchi, T.; Nagao, Y.; Abe, K.; Imazeki, F.; Honda, K.; Yamasaki, K.; Miyanishi, K.; Taniguchi, E.; Kakuma, T.; Kato, J.; et al. Effects of branched-chain amino acids and zinc-enriched nutrients on prognosticators in $\mathrm{HCV}$-infected patients: A multicenter randomized controlled trial. Mol. Med. Rep. 2015, 11, 2159-2166. [CrossRef] [PubMed]

34. Suzuki, H.; Asakawa, A.; Li, J.B.; Tsai, M.; Amitani, H.; Ohinata, K.; Komai, M.; Inui, A. Zinc as an appetite stimulator - the possible role of zinc in the progression of diseases such as cachexia and sarcopenia. Recent Pat. Food Nutr. Agric. 2011, 3, 226-231. [CrossRef] [PubMed]

35. Gadelha, A.B.; Vainshelboim, B.; Ferreira, A.P.; Neri, S.G.R.; Bottaro, M.; Lima, R.M. Stages of sarcopenia and the incidence of falls in older women: A prospective study. Arch. Gerontol. Geriatr. 2018, 79, 151-157. [CrossRef] [PubMed]

36. Vasto, S.; Candore, G.; Balistreri, C.R.; Caruso, M.; Colonna-Romano, G.; Grimaldi, M.P.; Listi, F.; Nuzzo, D.; Lio, D.; Caruso, C. Inflammatory networks in ageing, age-related diseases and longevity. Mech. Ageing Dev. 2007, 128, 83-91. [CrossRef] [PubMed]

37. Frazzini, V.; Rockabrand, E.; Mocchegiani, E.; Sensi, S.L. Oxidative stress and brain aging: Is zinc the link? Biogerontology 2006, 7, 307-314. [CrossRef] [PubMed]

38. Aydemir, T.B.; Troche, C.; Kim, J.; Kim, M.H.; Teran, O.Y.; Leeuwenburgh, C.; Cousins, R.J. Aging amplifies multiple phenotypic defects in mice with zinc transporter Zip14 (Slc39a14) deletion. Exp. Gerontol. 2016, 85, 88-94. [CrossRef] [PubMed]

39. Christensen, K.; Doblhammer, G.; Rau, R.; Vaupel, J.W. Ageing populations: The challenges ahead. Lancet 2009, 374, 1196-1208. [CrossRef] 
40. Osaki, Y.; Nishikawa, H. Treatment for hepatocellular carcinoma in Japan over the last three decades: Our experience and published work review. Hepatol. Res. 2015, 45, 59-74. [CrossRef] [PubMed]

41. Fukui, H.; Saito, H.; Ueno, Y.; Uto, H.; Obara, K.; Sakaida, I.; Shibuya, A.; Seike, M.; Nagoshi, S.; Segawa, M.; et al. Evidence-based clinical practice guidelines for liver cirrhosis 2015. J. Gastroenterol. 2016, 51, 629-650. [CrossRef] [PubMed]

42. Tieland, M.; Trouwborst, I.; Clark, B.C. Skeletal muscle performance and ageing. J. Cachexia Sarcopenia Muscle 2018, 9, 3-19. [CrossRef] [PubMed]

43. Kamo, N.; Kaido, T.; Hamaguchi, Y.; Okumura, S.; Kobayashi, A.; Shirai, H.; Yao, S.; Yagi, S.; Uemoto, S. Impact of sarcopenic obesity on outcomes in patients undergoing living donor liver transplantation. Clin. Nutr. 2018. [CrossRef] [PubMed]

44. Polyzos, S.A.; Margioris, A.N. Sarcopenic obesity. Hormones (Athens) 2018, 17, 321-331. [CrossRef] [PubMed]

(C) 2019 by the authors. Licensee MDPI, Basel, Switzerland. This article is an open access article distributed under the terms and conditions of the Creative Commons Attribution (CC BY) license (http://creativecommons.org/licenses/by/4.0/). 